ISSN: 1991-0037

SOUTH ASIAN JOURNAL OF NGRICULTURE

An Open Access Peer Reviewed Journal

South Asian J. Agric.

Short Communication

Vol. 7, No. 1\&2, 2016-'19 : 34-37

\title{
Livelihood Pattern of Betel Leaf Cultivators: A Case Study at Fakirhat Upazila in Bagerhat District of Bangladesh
}

\author{
Authors: Tuhin Roy*, Chowdhury Anowarul Alam and M.M. Abdullah Al Mamun Sony \\ Sociology Discipline, Khulna University, Khulna-9208, Bangladesh \\ *Corresponding author: Tuhin Roy; E-mail: tuhinroy41@gmail.com
}

\section{A B S T R A C T}

\author{
Received: \\ 15 November, 2018 \\ Accepted: \\ 05 January, 2019 \\ Online: \\ 31 March, 2019 \\ Key words: \\ Betel leaf, Cultivation, \\ Economy, Livelihood, \\ Occupation
}

Betel leaf is a traditional cash crop in Bangladesh. Betel leaf cultivation is such like traditional agro-based occupation. This cash crop is locally known as pan and it's scientific name is Piper betel that is the leaf of a vine belonging to the Piperaceae family. This study makes a modest attempt to know the livelihood pattern of betel leaf cultivators of south-west region of Bangladesh. The data were collected from Maskata Village in Betaga Union and Piljanga Village in Piljanga Union under Fakirhat Upazila in Bagerhat District, Bangladesh. This study was descriptive in nature. The paper is based upon qualitative approach which includes analysis of existing secondary sources of data. It also deals with primary data collected through Case Studies, Focus Group Discussions (FGDs), Key Informants Interview (KII) methods. The data were analyzed into five categories including: natural capital, financial capital, social capital, physical capital and human capital. Betel leaf cultivation is an ancestral occupation of the respondents. Most of the family structure is nuclear and have strong bonding within community. Poor socio-economic conditions include lack of sanitation, unavailability of pure drinking water and lack of health care center creates pressure on their health status. On the contrary, low education, poor savings and poor credit facilities with high rates of bank interest makes them more vulnerable. Water logging and rot diseases are other challenges of this cultivation. The children who are involved in tertiary education, they mostly not come back their ancestral occupation. From the study it is revealed that, integrated as well as comprehensive intervention program with social awareness and safety net program should be run by the Government and NGOs for the betterment of this vulnerable occupation. Moreover, health worker should provide medicine and other health incentives for physically vulnerable groups. This paper would contribute to the policy making and taking necessary initiatives especially for this occupational groups.

To cite this article: Roy, T., Alam, C.A. and Sony, M.M.A.A.M. 2019. Livelihood Pattern of Betel Leaf Cultivators: A Case Study at Fakirhat Upazila in Bagerhat District of Bangladesh, South Asian J. Agric., 7(1\&2): 34-37.

\section{INTRODUCTION}

Livelihood pattern is a complex process which includes social, economic, political, cultural, and technical and every aspects of life. When it implies for Bangladesh it is also very important because most of the people's status, like all over the world, determines according to their occupation, even their living settlements are shaped up by occupation (Science toy Maker, 2018). As a result, there have been seen high occupational variation in Bangladesh, one of the biggest delta among the world with 147,570 sq.km. land area, (Banglapedia, 2016; Kibria, 2012; Nishi, 2018). Betel leaf cultivation is such like traditional agro-based occupation in Bangladesh (Nishi, 2018). Besides, it is also one of cash crops. It has been quantified by Islam and Nath (2014) that nearly $71 \%$ of Khasia communities mean annual income was derived from betel leaf cultivation.

The betel leaf locally known as pan and it's scientific name is Piper betel that is the leaf of a vine belonging to the Piperaceae family, which includes pepper and kava (Megagroup bd, 2018; Karim, 2015). People use to take the heart shape leaf as a mild stimulant and/or medicinal feature. The heart shape leaf found an evergreen and creeper betel plant which is mostly cultivated in South Asia. Betel leaf requires high land and especially fertile soil. Waterlogged, saline and alkali soils are unsuitable for cultivation. People make barouj (especial place to cultivate betel leaf) which is fenced by bamboo sticks and coconut leaves (Karim, 2015; Megagroup bd, 2018). As, it is a creeper plant it requires a stick or tree to stand or grow up. It is consumed with or without tobacco in an addictive psycho-stimulate and euphoriainducing formulate causing adverse health effects (Karim, 2015; Megagroup bd, 2018).
Again, Karim (2015) argued that "the socio-economic history of betel leaf cultivators belongs to an occupational caste called Barui and all Baruis were originally Hindus most of them belonged to Nabasak caste and hold fairly higher position in the caste. In nineteenth century many of them became Zamindars (landlord) and tenure holders. During Muslim era they were the richest people among the cultivating classes because demand for pan was quite universal at that time. Most numerous among the pan producing Baruis, according to the censuses of 1872 and 1881, lived in Burdwan, Midnapur, Jessore and Dhaka. Since 1947 many Baroujes were abandoned or sold by the original Baruis and their estates were bought off by the entrepreneurial Muslims. Moreover, pan production is predominantly in the hands of the Muslim farmers but the technique of production remained unchanged. Among all the ethnic tribes living in Bangladesh Kashia's are lone community involved in betel leaf cultivation and it is their main occupation. They call this cultivation as pan jum. Their pan is very popular in Sylhet region and beyond for its good taste and strong bleaching quality (Karim, 2015).

In Bangladesh there were 187898 metric ton of betel leaf produced in 2014-2015 (Bangladesh Bureau of Statistics, 2016). About 57,354 acres of land were used to cultivate betel leaf during this period while in 2013-2014 total 57,212 acres of land were used to cultivate betel leaves. Among them the Bagerhat district covered 2,162 acres of land and produced 4,422 metric tons of betel leaf in the year 2014-2015 (Bangladesh Bureau of Statistics, 2016). 
In addition, agriculture sector contributes about $17 \%$ to the country's Gross Domestic Product and employs more than 45\% of total labor force (Bangladesh Bureau of Statistics, 2016). Therefore, scientists' attention graved by this specific group of people. Islam and Nath (2014) disclosed the livelihood pattern of Khasia community in Sylhet. They found the economy of the Khasia was forest-based. They were largely dependent on betel leaf hill farming in Lawachara National Park (LNP). Nath and Inoue (2009) found that Khasia community of Bangladesh have few ownership of land. Through a comparative study between betel leaf cultivators and non-betel leaf cultivators in Teknaf peninsula of Bangladesh it also found that the socioeconomic status of betel leaf cultivator is lower than non-betel leaf farmers (Rahman et al., 2016). Sakamoto et al. (2014) identified the consequence of betel leaf cultivation as a contributor of forest degradation. But betel leaf is a profitable cash crop (Islam et al., 2015). Ali (2014) conducted a study on betel leaf with a view to determine the problem confrontation of the betel leaf cultivators and to explore the relationships between the selected characteristics of the betel leaf cultivators and their problem confrontation in betel leaf cultivation. It was explored that the betel leaf cultivation is influenced by some physical and socio-economic factors. Unlike many other crops, its cultivation requires intensive and constant care from the farmers and is associated with a number of superstitions. Betel leaf is highly susceptible to some diseases, pests, and some natural calamities (Zaman, 1988). Through another comparative study it also concluded that, betel leaf cultivation is more profitable than cultivation of other crops (Islam et al., 2015). None of the researchers identified the livelihood pattern of the betel leaf cultivators, considering this points of view this research was intended with following specific objectives.

i. To identify the livelihood pattern of the betel leaf cultivators;

ii. To analyze the socio-economic conditions of the betel leaf cultivators; and

iii. To investigate the hindrances they are facing to lead their livelihood.

\section{METHODOLOGY}

The nature of this study is descriptive. Basically data were collected from primary and secondary sources. Primary data were collected from Maskata village of Betaga unions and Piljanga village Piljanga union at Fakirhat Upazila (sub-district) in Bagerhat district of Bangladesh (Fig. 1). The Betel leaf cultivators are the unit of the study. The qualitative instruments, i.e., case study, focus group discussion (FGDs) and key informants interviews (KIIs) were adopted to get the intensive information about the livelihood pattern of betel leaf cultivators in this study area of Bangladesh. To illustrate the current situation, by using case study it was tried to point out the living mechanisms that betel leaf cultivators use to cope with the environment. On the other hand, FGDs and KIIs were used to get an in-depth and comprehensive data about the problems and prospects of the cultivators. To fulfill this purpose, four case studies, two FGDs and two KIIs in each village (total 8 case studies, 4FGDs and 4 KIIs) were conducted by using purposive sampling. Each of the respondents was betel leaf cultivator and head of the household. The respondents were purposively selected. Each of the selected respondents was informed formally to attend a particular place to participate in the FGD group. They were also informed about the objectives of the study in details before the meeting. Moreover, to conduct the focus group discussion, along with chief researcher, two research assistants were also present there as a note taker. However, to conduct KII especially knowledgeable persons such as teachers, a union parishad chairman and a union parishad member were selected. After conducting this study, data were processed and analyzed.
Field work of this study was conducted between February to March of 2018. In this study the livelihood pattern was analyzed by five capital assets which represented all of materials, services, and opportunities available to people to use in meeting their basic needs, and in mitigating or adapting to disruptive changes.

Natural Capital: land, water, biological resources (biodiversity); Financial Capital: stocks of money or assets in liquid form; Social Capital: rights or claims derived from group membership; Physical Capital: infrastructure; resources created through economic production;

Human Capital: quantity and quality of labor available (Scoones, 1998).

The study therefore aims at to assess the livelihood pattern of betel leaf cultivators in Bangladesh. Secondary data were collected from several Bengali and western literatures, research papers, dissertations, newspapers, magazines and so on.

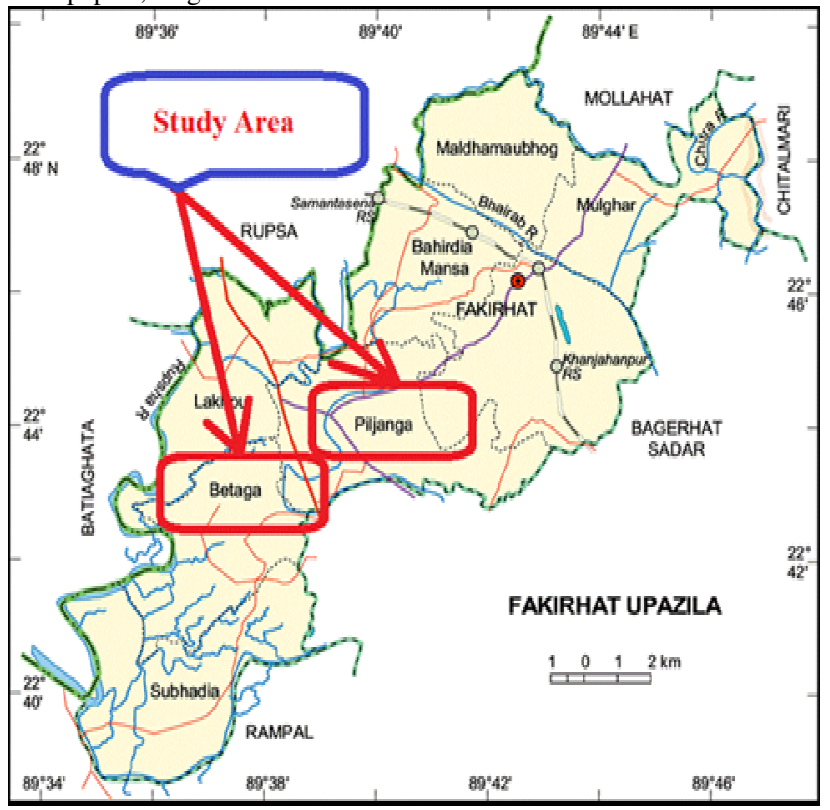

Fig. 1 Map of Betaga unions and Piljanga union at Fakirhat upazila (subdistrict) in Bagerhat district of Bangladesh (Banglapedia).

\section{RESULTS AND DISCUSSION}

\section{Natural Capital}

Through this study it is evident that betel leaf cultivation is the hereditary occupation in the study area. Most of the respondents and key informants mentioned that their father and grandfather involved with betel leaf cultivation but they can hardly remember the actual time when their ancestor began betel leaf cultivation. Again, through FGD it was found that few people newly involved with this cultivation because it was comparatively profitable and produce less risk. They mentioned that soil and climate of Bagerhat district is suitable for betel leaf cultivation. They think that betel leaf cultivation is helpful to increase social status.

\section{Financial Capital}

Maximum respondents had only one borouj but a few of them had two borojs. All respondents addressed that these boroujes were their main income source. The findings of the first case study exhibit that the annual profit of last year was approximately 1,70,000 BDT from 76 satak borouj and from the findings of sixth case it was evidenced that annual profit in last year was approximately $65,000 \mathrm{BDT}$ for 25 satak boroj. According to this information their average income from borouj were 2,400 BDT per satak (unit of area). All respondents argued that their profits were higher in last year compare to this year. The economic conditions of most of the respondents controlled only by betel leaf cultivation but few respondents mentioned they have multiple source of income too. They did it because of risk management. Rice harvesting were an example of complimentary cash crops. 
Apart from cultivation, some of them were also involved in little business like, shop keeping, van pulling and so on as alternative source of income. All the respondents came to one conclusion that their family members (wife and other female family members) reared cattle and pet birds to fulfill their nutrition. In addition, few respondents used to sell milk of cattle and eggs of birds in market for more money but not for family nutrition. These were their additional source of income. About the ownership of cultivable land, they told that they have much more tenant land rather than their own land. But everyone had own homestead. They had no chance for saving money because their income was limited compare to expenditure. Besides, three respondents saved very little amount of money. They are not involved with any kind of social organization and they did not get loan facilities from any Bank and NGOs specifically for betel leaf cultivation. Four respondents argued that for their children's tertiary education they obtained little amount of scholarship from Bank and NGOs. In emergency cases, they got financial support from their relatives and neighbors with or without interest.

\section{Social Capital}

This study identified the overall livelihood pattern of betel leaf cultivators. Two third of respondents belonged to Vaishyas caste of Sanatana religion and rest of the respondents were Muslim. Maximum respondents' families were nuclear family in nature. While, few number of families were extended. As maximum families were nuclear there they had only one earning member but in cases of extended families there were more than one earning members. The relationship among their neighbors was almost good and they were cooperative with each other, that means, when they face problems, their neighbors support them (financial or non-financial support) which is very effective. For recreation the respondents usually passed their free time in the nearest shop or market, they used to play carom, cards, and watch TV. The findings of key informants and group discussion reveal that the common diseases of betel leaf cultivators were diabetes, blood pressure, headache, stomach problems, acidity problems and so on.

There was no qualified experienced doctor or private clinic in the study area. When they suffered fatal diseases, they go to hospital for treatment in Fakirhat upazila hospital which is far from their village and when the situation became very complicated, they used to go to Khulna Medical College Hospital. Women less likely went to hospital during their pregnancy period, they are highly depended on local midwife during their parturition. The people were less careful about childbearing mother. Though the respondents were not well educated but they were interested to educate their children and they sent their children to school. But in few cases, they did not send their children to school for financial problems. There are two primary schools and two high schools in Maskata village. No evidence was found that their children are discriminated in school. Four respondents' children were pursuing tertiary education and one of them addressed his son pursuing postgraduation in Khulna University.

\section{Physical capital}

The housing structure of the respondents was both brick-built and mudbuilt houses. Those who are well off enough they constructed brickbuilding house. Most of the families used bricks for wall and floor but tin were used for the roof; besides, some family also lived in huts. The space in their house was not sufficient; they have scarcity of room space in their house. From focus group discussion it was clear that very few pure water sources were there. Thus, they used to collect drinking water from long distance. Particularly female members used to do this job but sometimes their men assisted them. In addition, female members enjoyed to do this because they used to go with in group and then they talk and exchange their feelings with each other. On the contrary, maximum respondents were not conscious about healthy sanitation systems. Literally, their sanitation facilities were very poor but they said that it was enough. Besides, very recent they got the electricity in their households.

\section{Human capital}

Maximum female members of the family used to count and prepare betel leaf to sell in the market but they are usually considered as unpaid labor. All the respondents used to take three times meal in a day like other villagers. Moreover, their first meal was lunch because very early in the morning they worked in the field. They usually take fish and vegetables and sometimes take meats. In addition, they cultivate rice for the purpose of annual consumption. Few respondents said that they planted vegetables beside their house to fulfill their family needs. Basically women take this responsibility and male hardly help with them. Some of them opined that, they used to catch fish from pond, cannel and bill for their family. They believed that it was more profitable to sell eggs and milk which they get from cattle and pet birds. Maximum respondents believed that it was not necessary to take milk or an egg regularly which implies that they have poor knowledge about nutrition. Due to poor financial conditions they do not go to have meal in a restaurant and do not arrange any family picnic. They think that it was not good to do it because religion does not allow it. Besides, those people liked to do such activity as the community do not consider them as civilized person. It was also observed that all respondents consumed betel leaf habitually. Through FGD it was found that the community allows consuming betel leaf after certain age. Besides, they offer betel leaf with betel nuts to their guests. Not only this but also they are more friendly towards their guests and curious about visitors. After regular meal they are used to take one piece of betel leaf. Finally, the people of this community use three-wheeler as a transport system to carry their betel leaf to their local market.

\section{Hindrances of this occupation}

Few hindrances are also being faced by them to cultivate betel leaf that includes natural disaster, waterlogging, flood and so on. Waterlogging caused by excessive rainfall is the main problem of this area. Scratch and rotten disease of betel leaf and high price of borouj materials causing the of cultivation of betel leaf vulnerable. The rise and fall of market price caused by middleman created low profit for a base level cultivator (Islam et al., 2015). Lack of social security and less or no support from government make a crisis in the society. They are used to cultivate in traditional way but they felt a lack of scientific study as it is one of the cash crops in our country. One respondent mentioned that with the help of union parishad chairman they got few security guards to guard their borouj at night. They believed that as they have no political person from their community so there is no government attention to them. Therefore, migration towards town and shifting the occupation is very common among them.

\section{CONCLUSIONS}

Today is the age of modernization; the people all over the world are being facilitated by education, science and the development of modern technology. The betel leaf cultivators at Fakirhat Upazila in Bagerhat District involves traditionally in this occupation. They hardly change this occupation though they have lots of challenges. Due to lack of special attention like community clinic, complications during pregnancy is very common and they are not even conscious about family planning. Poor child nutrition made their future generation vulnerable. Poor market conditions pushes them to shift their occupation and sell the lands too. Though this occupational group contributing a handsome number in GDP of Bangladesh but graved little attention to protect this occupation. They need to develop their housing structure so they need financial supports. Attention is necessary to combat diseases and natural disaster hindering the cultivation of betel leaf. They are facing many problems in cultivating betel leaf. They traditionally combat with natural disaster but hardly overcome this situation. Lack of social awareness and superstation make them to remain step-asides. Their socio-economic conditions are being vulnerable day by day. 
Social awareness program and safety net program should be run by the Government and NGOs for the betel leaf cultivators specifically. Health workers should provide medicine and other health incentives for physically vulnerable group. Bank and NGOs need to focus on this field to provide financial supports. More attention needs to develop infrastructure too. So, further comprehensive study is needed to know their actual problem both in social and economic aspects

\section{REFERENCES}

Ali, M. Y. 2014. Problem confrontation in betel leaf cultivation by the farmers of Natore district. Sher-e-Bangla Agricultural University, Agricultural Extension and Information System, Dhaka.

Bangladesh Bureau of Statistics (BBS). 2016. Yearbook of Agricultural Statistics 2015. Statistics and Informatics division, Ministry of Planning, government of People's Republic of Bangladesh. Dhaka, Bangladesh.

Banglapedia. 2016. Bangladesh geography. Retrieved from Banglapedia.org. Available at: http://en.banglapedia.org/.

Islam, M. and Nath, T. K. 2014. Forest-based betel leaf and betel nut farming of the Khasia indigenous people in Bangladesh: approach to biodiversity conservation in Lawachara national park (LNP). Journal of Forestry Research, 25(2): 419-427.

Islam, Q., Matin, M., Rashid, M., Hoq, M. and Zaman, M. 2015. Profitability of betel leaf (Piper betle L.) cultivation in some selected sites of Bangladesh. Bangladesh Journal of Agricultural Research, 40(3): 409-420.

Karim, A. E. 2015. Pan1. Retrieved from Banglapedia.org. Available at: http://en.banglapedia.org/.

Kibria, A. 2012. Occupational inequality in Bangladesh society: a quantitative analysis. UITS Journal, 1(2): 7-21.

Megagroup bd. 2018. Our export product: betel leaf. Retrieved from Mega Group BD.com. Available at: http://www.megagroupbd.com/.

Nath, T. K. and Inoue, M. 2009. Sustainability Attributes of a Small-Scale Betel LeafAgroforestry System: A Case Study in North-eastern Hill Forests of Bangladesh. International Union of Forestry Research Organisations. Small-scale Forestry Group, Springer Verlag, 8(3): 289-304.

Nishi, A. 2018. Betel leaf cultivation on rise in Dinajpur. Daily Bangladesh. Retrieved from Daily-Bangladesh.com. Available at: https://www.daily-bangladesh.com/.

Rahman, M. A., Tani, M. and Tsuruta, H. 2016. Socioeconomic characteristics of the betel leaf farmers in the Teknaf peninsula, Bangladesh. Asian Journal of Agricultural Extension, Economics \& Sociology, 11(3): 1-8.

Rahman, M. A., Tani, M., Asahiro, K., Tsuruta, H. and Ullah, S. A. 2014. Farmers' experiences on problems and prospects of betel leaf cultivation in Teknaf peninsula of Bangladesh. Proceedings of $5^{\text {th }}$ International Conference on Environmental Aspects of Bangladesh [ICEAB 2014], Kyushu University, Fukuoka, Japan. pp. 60-62.
Science toy Maker. 2018. Occupations in Bangladesh. Retrieved from Sciencetoymaker.org. Available at: https://sciencetoymaker.org/.

Scoones, I. 1998. Sustainable Rural Livelihoods: A Framework for Analysis. IDS Working Paper 72.

Sakamoto, M., Tani, M. and Moriyama, M. 2014. Examining the process of deforestation by cash crop farming in teknaf and its impact on inhabitants' livelihoods. International Journal of Environment, 4(2): 31-38.

Zaman, S. U. 1988. An Economic Geographical Study of Betel Leaf Cultivation in Bangladesh. B. Sc. Thesis, Department of Geography, University of Dhaka, Dhaka. 